\title{
Gender Competence of the Modern Teacher
}

\author{
Ludmila A. Auhadeeva ${ }^{1}$, Iskander E. Yarmakeev ${ }^{1} \&$ Aver E. Aukhadeev ${ }^{2}$ \\ ${ }^{1}$ Institute of Philology and Intercultural Communication, Kazan (Volga Region) Federal University, Kazan, \\ Russia \\ ${ }^{2}$ Kazan State Power Engineering University, Kazan, Russia \\ Correspondence: Iskander E. Yarmakeev, Institute of Philology and Intercultural Communication, Kazan (Volga \\ Region) Federal University, Kazan, Russia. Tel: 795-0323-4229. E-mail: ermakeev@mail.ru
}

Received: October 11, 2014 Accepted: November 17, 2014 Online Published: January 27, 2015

doi:10.5539/ies.v8n2p32 URL: http://dx.doi.org/10.5539/ies.v8n2p32

\begin{abstract}
This article discusses improvements in education and modern teacher's gender training in terms of a competencebased approach as a basic strategy of general and vocational education development in Russia. The article substantiates the relevance of teachers' gender training and the necessity to use the gender approach in their professional activities. It also focuses on the basic idea of the gender approach, its goals, importance of the gender approach for successful gender socialization, self-actualization, and self-identity of students. The article presents the results of diagnosing the current state of application of gender mainstreaming in modern school practices and attitudes of teachers and students to this issue. The gender approach requires targeted training for teachers as well as the development of a gender competence seen as a prerequisite for improving the quality of modern teacher training. It is one of the main areas of modernization in teacher education.
\end{abstract}

Keywords: education, multicultural educational space, competence approach, gender approach, gender socialization, gender competence, gender stereotypes

\section{Introduction}

UNESCO's World Conference adopted The World Declaration on Higher Education declaring the Twenty-First Century the century of education. Consequently, the world civilization is experiencing a real "education boom" caused by the birth of the "information society", a revolution in techniques, technology, and economy, our altered understanding of human rights, freedoms, personal duties and responsibilities. World priorities in education are also changing. Global and European trends of education development are defined and the leading role of liberal education is recognized. Globalization, as a worldwide phenomenon, has brought the issue of global education to the foreground. At present, education functions as a multicultural and educational space, which is a special sphere where individual consciousness enters global public consciousness, the sphere of dialogue among cultures and mentalities based on harmony, integration, human unity, and readiness for personal-professional development (Auhadeeva, 2014).

Improvement of education is regarded as a prerequisite for social progress and a key factor in the development of mankind.

The main trend of modernization in Russian education is improvement in the quality of professional education, especially teacher education, as a determinant of educational efficiency and potential of the whole system of national education.

The necessity of improving the quality of professional education is determined by a number of factors: socio-economic changes in the country; Russia's entry into a Common European Space in Higher Education; the competency-based approach as a basic strategy for the development of general and professional education, etc.

The competency-based approach is based on the competences of a person, the formation of whom is the purpose and outcomes of education. The Steering Committee for Higher Education and Research of the Council of Europe considers competences to be essential components of a quality education.

A number of researchers consider Aristotle to be a founder of the competency approach, as he studied the possibilities of the human condition denoted by the Greek word "atere"-"the force that develops and improves to such an extent that it becomes a quality of the individual." 


\section{Literature Review}

The development of the competency-based approach in education is connected with such concepts as "competence", "communicative competence" introduced into the scientific terminology of the theory of language (Chomsky, R. White, etc.) and the development of the concept "social competence of being competent" (White, 1959).

John Raven has 37 competencies, noting that some of them may be related to the intellectual sphere, while others may be related to the emotional sphere. They can replace each other, and represent "motivated abilities." He defines competence as a certain ability which is necessary to perform a particular action in a particular domain and which includes highly specialized knowledge, special kinds of subject skills, ways of thinking, as well as a sense of responsibility for one's own actions. (Raven, 1998)

According to the German researcher Ute Clement, the "attractiveness" of the term "competence" in comparison with the term "qualification" is in its "open and inclusive meaning": "If "qualification" describes the functional correspondence between the demand for jobs and special purposes of education, "competence" should include the ability to act adequately to the situation in broad areas." (Ute, 2002)

Some of the current trends in the development of modern educational theory and practice is a gender pedagogy. Gender approach, gender relations, gender education and gender competence have become the subject of foreign and Russian researchers (for example, Auhadeeva \& Zakirova, 2013; Bobovnikova \& Bocharova, 2011; Gurian, 2004; Haste, 2013; Holfve-Sabel, 2012; Lahelma, Lappalainen, Palmu, \& Pehkonen, 2014; Mudric, 2003; Klecina, 2004; Starovoitova, 2006). They focus on the features of training and education of children of both sexes.

In modern sociological literature, the term "gender" is often used to distinguish "biological" from "social" sex, the meaning developed by such social institutions as the family, education, media, politics, etc.

According to Russian researchers, the distinction between sex and gender is the following: sex is determined by physical differences between man and woman, and the notion of "gender" reflects their psychological, social, and cultural characteristics.

Gender Strategy of the Russian Federation (2004) emphasizes the importance of reforming the education system based on gender-oriented programs that promote free spiritual development and a gender perspective in the curriculum of all institutions of higher education. The gender approach is seen as one of the ways leading to personality development that meets international standards.

It brings to the foreground the issue of improving the quality of training a teacher to be able to implement the gender approach in modern schools and formation of a gender competence as an important component of the overall cultural competence in a modern professional employee (Fahrutdinova, Fahrutdinov, \& Konopatskaya, 2014).

The basic idea of the gender approach in pedagogy is to take into account the influence which interrelations have on both males and females in all aspects of educational activities: content, forms, methods of training, technologies of educational process organization, pedagogical communication, as well as traditional gender stereotypes. They are understood as the standardized representation of behaviors and character traits corresponding to the concepts of "masculine" and "feminine." Those gender stereotypes are the most striking and effective mechanisms for the development of traditional gender roles and social behavior. (Voronina, 2005)

Stereotypes are recognized and acquired by the individual in the course of gender socialization. The educational system, as a leading institution of socialization, plays a key role in this process.

Comprehensive school is the basic model of the social world, where children act as subjects of public relations, and where the skills of interaction with people of both sexes are developed. School is a place where traditional gender stereotypes get fixed in the child's mind, where behaviors are practiced. They determine not only the success of interaction with the outside world in the present and in the future, but also the opportunities for personal and professional self-improvement. Therefore, individual characteristics and abilities of boys and girls should be taken into account while organizing educational activities at schools, and creating a gender-friendly learning environment. This goal will be achieved if both female and male teachers educate children at schools. The role of male teachers is particularly great: they not only perform their professional duties, but also set an example for boys in male behavior, communication, attitude to work and life in general. In this case, gender stereotypes will play a positive role. This fact can greatly influence the effectiveness of gender socialization.

The gender approach in educational activities is aimed at creating conditions for educating boys and girls whose 
development and spiritual value orientation will contribute to the manifestation and possession of positive individual masculine, feminine and androgynous features. It is also a means of successful adaptation of younger generation to the realities of sex-role attitudes and effective sex-role insulation in society (Mudrik). The priorities in the education of boys and girls are not fixed standards of masculinity and femininity, but the study of potential partnerships between boys and girls (Bobovnikova etc.).

Thus, the gender approach in education aims to promote schoolchildren's individual manifestations of gender characteristics (masculine, feminine, androgynous), their freedom of expression and the development of the qualities that may go beyond gender stereotypes, which means successful gender socialization, self-actualization and self-realization.

We define gender socialization as a process of personality development and self-development that is realized in the system of relationships with adults, peers and oneself in accordance with individual and gender characteristics.

Even a cursory analysis of the content of the existing textbooks in the humanities with respect to the implementation of the gender approach shows that they do not focus on education and upbringing of boys and girls (Kovalenko et al., 2014).

Russian researchers understand the gender approach in pedagogy in terms of the concept of "gender identity." In this case, special attention is paid to the individual approach to children's manifestation of their gender identity. It should be noted that gender identity is not uniform, the same for all people within the same sex. Researchers recognize the multiplicity, individuality, and plasticity of gender differences. According to Kostikova, "it is not that representatives of different sexes need a differentiated approach on the part of the teacher, the point is, they have to face the complex world of changing gender stereotypes that come into conflict with their personal desires and inclinations. The goals of the gender approach in education are to explain the nature of these stereotypes, to show their variability and social conditioning." (Kostikova, Mitrofanova, Pulína, \& Gradskova, 2001, pp. 68-70)

\section{Methods}

An important problem of gender education today is that traditional gender stereotypes that do not correspond to the world realities and modern trends in society. They reflect the past, make gender socialization difficult, and limit the abilities of pupils in the area of self-development and self-realization. Today, traditional gender socialization of girls and boys reproduces patriarchal stereotypes of gender interactions in public and private spheres, which contradict the existing transformation of gender relations in modern society and which are an obstacle to the disclosure of personality, gender equality, and steady development of democratic relations.

Modernization of stereotypes should be taken into account as they reflect gender reality and make it possible to predict the future of gender. Acceptance of the modernization of stereotypes, of their diversity and the development of tolerance in teachers and schoolchildren can change the pattern of relations between sexes and ensure the implementation of positive gender capacity of the younger generation.

Implementation of the gender approach in education means acting with understanding of the social origin of "male" and "female" categories in the community. It also means putting the personality and individuality of the child in its development and education above the traditional boundaries of sex. School should give children an opportunity to develop their individual abilities and interests, regardless of sex affiliation. It should oppose traditional standards with respect to sexes. To do this, the modern teacher should have gender competence and knowledge of the technologies of the gender approach applied to the process of socialization of boys and girls.

It is necessary to make a diagnosis of the state of pedagogical reality to organize targeted training of future teachers in using a gender perspective in their professional activities. The following methods were used to conduct this research: S. Bem's test for gender identity (a questionnaire of gender roles BSRI), which determines the type of personality and reveals the degree of masculine and feminine characteristics; Freiburg Personality Inventory (FPI), which defines masculine-feminine personality traits; Leary test (modified by Reshetnyak and Vasilchenko) aimed to study gender features and characteristics in the personality structure; the questionnaire "Proverbs" (Kletsina) for the study of gender attitudes; Boyko communicative tolerance test and a communicative control test to determine communicative qualities, communicative tolerance, and the level of communicative control as leading indicators of a gender competence.

As research platforms, we had 10 schools: high schools No 7 and No 12; secondary schools No 1, 9, 72, and 99 (Kazan, the Republic of Tatarstan, Russian Federation); Humanitarian boarding school for gifted children (Aktanysh, the Republic of Tatarstan, Russian Federation) etc. About 300 people have participated in the survey. 


\section{Results and Discussion}

The results showed that all teachers have pronounced feminine and masculine personality traits and adhere to traditional gender stereotypes. And this, of course, has a significant influence on gender socialization of pupils and the formation of gender attitudes and values among them.

All participants (100 per cent) noted that there are differences in their schoolchildren's education and upbringing and, in their opinions, the gender approach is a necessary component of pedagogical activities in the modern school. It determines the effectiveness of educational activities and gender socialization of pupils.

The majority of teachers (90 percent) want to expand their body of knowledge about the features of gender socialization and the implementation of the gender approach in modern schools. They ascertain the lack of scientific and methodical literature and pedagogical support on this problem. Only 10 percent of the respondents say that they successfully applied a gender perspective in their work.

According to the results of research on communicative qualities, 25 percent of the teachers have a high level of communicative tolerance, 62.5 percent have an average level, and 12.5 percent have a low level. As for communicative control tests, 5 percent of the teachers have a high level, 85 percent have an average level, 10 per cent have a low level of communicative control.

The results of the survey of senior schoolchildren revealed that 83 percent are familiar with the masculinity and femininity concepts and 61 percent of the schoolchildren believe they possess them. However, according to our study, there is a serious problem: modern girls and boys do not know how to express their femininity or masculinity and do not realize how important these personal qualities are. For example, girls responded to femininity in a critical manner, considering it to be a sign of weakness and an obstacle to becoming socially successful. Moreover, they criticized boys' masculinity. Boys associated their male authority mainly with social success, ignoring other qualities and abilities (empathy, communicative skills, and credibility in other ways than manifestation of their social success). Boys do not know other ways to generate and recognize dignity, confidence, and courage if there is no material success. Thus, there is a clear lack of moral values and attitudes in boys and girls, which complicates the process of forming a positive personality and gender identity.

Most of the respondents (98 percent) expressed a positive interest in a more detailed study of the gender concepts, gender personality traits and gender approach in teaching. Only 2 percent of the children reported that the problem did not interest them.

An entire 100 percent of the surveyed schoolchildren admitted that there were differences between boys and girls, which were revealed in communication and relationships, learning and behavior. When it came to identifying way they studied school subjects, 88 percent identified differences; 96 percent reported differences in choosing a future profession, in housekeeping, and in parenting. Less than five per cent of the respondents indicated that there were no differences between boys and girls except biological ones.

The vast majority of the respondents (95 percent) think that the teacher has to take gender characteristics into account in educational and extracurricular activities. The majority of schoolchildren (79 percent) reported that teachers were friendlier in ratings girls owing to such stereotypes as "girls are more obedient", "girls do better at school, they are more careful", or the following ones: "boys are less diligent, more often distracted", "boys are often bullies". A lot of schoolchildren (69 percent) considered that teachers were more lenient to their "favorites" in the classroom, regardless of their gender. Only 10 per cent of the schoolchildren said that teachers favored boys. According to 8 percent of the schoolchildren, the school teachers' sexual identity did not affect their indulgent, friendly attitude to children.

Twenty per cent believed that the job of teaching was suitable both for men and women. Nearly 75 percent said that the job of teaching was predominantly a female profession. Less than 10 percent (7) said that such a profession was more suitable for men, as for them "sciences were easier to study." At the same time, 75 percent of the respondents answered that they would prefer to have female teachers; 15 percent preferred male teachers.

It should be noted that, despite the specificity of the different schools and their location (city of Kazan and Tatarstan Aktanysh) student responses coincide. In our opinion, this is because they are in a same socio-cultural and educational space.

Our research shows that gender-specific teachers should clearly understand their own gender identity, taking into account the impact of their gender attitudes on the development of gender attitudes and values in their schoolchildren. They should be aware of the possibilities gender pedagogy has to improve the quality of the socialization. A gender competence of the teacher means awareness of the organizational, psychological, pedagogical, and didactic aspects in managing schoolchildren's educational activities based on their 
gender-specific attitudes.

The results are important for defining conditions for implementing the gender approach in modern schools, for studying the extent of teachers' traditional gender stereotypes' influence on "teacher-pupil" interaction and the level of teachers' readiness to provide educational support of gender socialization. Firstly, these results will make it possible to determine factors and conditions for improving the quality of gender education for teachers. Secondly, they will enable us to design, develop, and implement the integrated technology of a gender competence development in the future teachers during their university preparation.

We consider gender competence to be a unity of knowledge, skills, and targeted pedagogical actions aimed at the implementation of the gender approach, gender socialization, as well as skills and experience required to carry out a gender strategy. The goal of gender competence is to fully discover and realize the uniqueness of each child in a holistic pedagogical process.

The current analysis shows that the desired level of the teachers' gender competence, their willingness to implement the gender approach in vocational, educational and social activities can be achieved if the design and organization of their education is realized as an integrated system, which includes principles, conditions, and technologies of gender competence development.

A gender competence influences communication culture, behavior and relationships as well as promotes the development of communicative humanistic core in the personality, increasing the level of communicative control and efficiency of interethnic communication (Auhadeeva, 2012).

In addition, the researchers consider gender competence to be an important factor in the development of tolerance, adequate cultural sensitivity, and success of cross-cultural communication. It is the basis for the development of intercultural competence (Khabutdinova \& Bayanova, 2013).

All of these determine the importance of the development of modern teachers' gender competence and their targeted training, which aims at the implementation of the gender approach in the comprehensive educational process.

\section{Conclusions}

Modern teachers should be able to implement organizational, psycho-pedagogical and didactic aspects of the gender approach, taking into account gender characteristics of their schoolchildren and the impact their gender attitudes have on the development of gender attitudes and values in schoolchildren. They should implement gender pedagogy in their teaching practices to improve the quality of education.

Gender pedagogy should be a component of the modernization in education, as it develops a different worldview and relationships with members of the opposite sex. And that, ultimately, should lead to a change in social consciousness.

Gender education is a phenomenon capable of transforming the existing education policy towards greater tolerance. It is necessary to correct the existing gender stereotypes in order to form a new personality (versatile, morally mature, and creative, conscious of their gender features and gender roles).

Targeted training of future teachers in implementing the gender approach at schools as well as the development of undergraduates' gender competence is important factors for improvement of higher pedagogical education.

\section{Acknowledgments}

The work is performed according to the Russian Government Program of Competitive Growth of Kazan Federal University.

\section{References}

Auhadeeva, L. A. (2012). Communicative aspect of teacher training. Moscow: VINITI.

Auhadeeva, L. A. (2014). Communicative Competency in Teacher Training. World Applied Sciences Journal, 31(4), 583-586. http://dx.doi.org/10.5829/2014.31.04.14330

Auhadeeva, L. A., \& Zakirova, A. R. (2013). Gender studies as an innovative approach in education. "Applied Sciences and technologies in the United States and Europe: Common challenges and scientific findings": Papers of the 1st International Scientific Conference (June 29, 2013 pp. 84-86). New York, USA: Cibunet Publishing.

Bocharova, N. M. (2011). The social aspect of gender approach in education. Chita.

Burn, S. M. (1996). The Social Psychology of Gender. New York: McGraw-Hill.

Fahrutdinova, R. A., Fahrutdinov, R. R., \& Konopatskaya, E. A. (2014). Formation of general cultural competencies of students in the educational space of the University. Life Science Journal, 11(6), 525-529. 
Retrieved from http://www.lifesciencesite.com/lsj/life1106/076_24749life110614_525_529.pdf

Gender Strategy of Russian Federation (Project). (2004). Moscow.

Gurian, M. (2011). Boys and Girls Learn Differently! A Guide for Teachers and Parents. San Francisco, CA: Jossey-Bass.

Haste, P. (2013). Sex education and masculinity: The 'problem' of boys. Gender and Education, 25(4), 515-527. http://dx.doi.org/10.1080/09540253.2013.789830.

Holfve-Sabel, M.-A. (2012). Gender attitudes in school have changed mainly in peer relational factors over a period of 35 years. Gender and Education, 23, 73-86. http://dx.doi.org/10.1080/09540251003675466

Khabutdinova, M. M., \& Bayanova, L. (2013). Norms and Values Characteristics of Students in a Foreign Cultural Environment. Middle-East Journal of Scientific Research, 16(11), 1527-1531. http://dx.doi.org/10.5829/idosi.mejsr.2013.16.11.12041

Klecina, N. T. (2004). The gender aspect of the relationship. S-Pb.

Kostikova, I., Mitrofanova, A., Pulína, N., \& Gradskova, Yu. (2001). Prospects of Gender Education in Russia. Vyssheeobrazovanie $v$ Rossii, 2, 68-75.

Lahelma, E., Lappalainen, S., Palmu, T., \& Pehkonen, L. (2014). Vocational teachers' gendered reflections on education, teaching and care. Gender and Education, 26(3), 293-305. http://dx.doi.org/10.1080/09540253.2014.901734

Lappalainen, S., Nietola, R., \& Lahelva, E. (2013). Gendered divisions on classed routes to vocational education. Gender and Education, 25(2), 189-205. http://dx.doi.org/10.1080/09540253.2013.740445.

Mudric, A. (2003). On gender role (gender) approach to social education. Vospitatel'nayarabota v shkole, 5 , 15-19.

Raven, J. (1998). Competence in Modern Society: Its Identification, Development and Releas. eHodder Arnold $\mathrm{H} \& \mathrm{~S}$.

Schiebinger, L. (Ed.). (2008). Gendered innovation in science and engineering. Stanford, CA: Stanford University Press. http://dx.doi.org/10.1080/09540253.2011.558739

Starovoitova, Zh. A. (2006). Conditions of the organization of the learning process in primary school on the basis of gender approach. Pedagogicheskiye nauki, 4(20), 136-140.

Ute, C., \& Rolf, A. (2002). Kompetenzentwicklung in der beruflichen Bilduns. Leske+Budrich. Opeade.

Voronina, O. A. (Ed.). (2005). Gender analysis of textbooks for high school. Moscow: ROO MCGI, OOO "Soltex".

White, R. W. (1959). Motivation reconsidered: The concept of competence. Psychological Review, 66(5), 297-333.

Zakirova, A. R., \& Auhadeyeva, L. A. (2013). Gender stereotypes and modern pedagogy. Philology and Culture, 2(32), 296-299.

\section{Copyrights}

Copyright for this article is retained by the author(s), with first publication rights granted to the journal.

This is an open-access article distributed under the terms and conditions of the Creative Commons Attribution license (http://creativecommons.org/licenses/by/3.0/). 